\title{
Uma Breve História da Engenharia Química
}

\author{
Alberto V. da Silva, Claudia G. D. de Abreu, Josie C. Barbosa, \\ Marta C. Picardo \& Ronaldo L. de Souza
}

No século XIX, a abordagem dos químicos em relação à produção química era semelhante à construção de um mecanismo, um processo de cada vez, separadamente e individualmente, como se cada processo fosse incompatível com todos os outros. A criação da engenharia química introduziu princípios científicos que tornaram possível generalizar práticas e racionalizar os processos de produção, levando ao desenvolvimento da indústria química.

Palavras chave: história; engenharia química; indústria química.

In the nineteenth century, the chemists' approach to chemical production was similar to building a mechanism, one process at a time, separately and individually, as if each process were incompatible with all others. The creation of chemical engineering introduced scientific principles that made it possible to generalize practices and rationalize production processes, leading to the development of the chemical industry.

Keywords: history; chemical engineering; chemical industry. 


\section{Introdução}

Desde o final do século XX, a engenharia se desdobrou em muitas ramificações, cada uma com um tipo distinto de tecnologia: civil, mecânica, química, elétrica, aeronáutica e aeroespacial, da computação, de produção, e outras tantas. As engenharias civil e mecânica são dois ramos dos mais antigos e têm suas raízes nas tarefas práticas. Já os ramos mais recentes encontram-se alinhados com a evolução da ciência e tecnologia.

Estudiosos interessados em modelagem cultural da tecnologia costumam especular sobre a existência de uma relação entre uma corrente filosófica em uma dada época e local com o nascimento de um ramo de engenharia ou de um tipo de instituição científica. Assim, é possível supor a existência das seguintes associações ocorridas no século XIX:

Tabela 1. Associações Ocorridas no Século XIX.

\begin{tabular}{|c|c|}
\hline Corrente filosófica & Ramo / Instituição \\
\hline Racionalismo francês & $\begin{array}{c}\text { Engenharia civil (orientação } \\
\text { matematizada); universidades } \\
\text { com perfil técnico }\end{array}$ \\
\hline Empirismo britânico & $\begin{array}{c}\text { Engenharia mecânica (orientada } \\
\text { para a experimentação), } \\
\text { sociedades profissionais }\end{array}$ \\
\hline Idealismo alemão & $\begin{array}{c}\text { Engenharia de materiais, } \\
\text { escolas de pós-graduação; } \\
\text { laboratórios de pesquisa básica } \\
\text { e pesquisa industrial }\end{array}$ \\
\hline Pragmatismo americano & Engenharia química; indústrias \\
\hline
\end{tabular}

Para investigar sistematicamente processos industriais de produção química, a engenharia química é única na integração da química com a física. Também o é na investigação da biologia molecular, pois integra a bioquímica com a genética. A engenharia química está bem preparada para os desafios do século XXI, em parte porque, desde o início, adotou-se o espírito aberto da ciência e encontra-se pronta a saltar sobre conhecimentos estratégicos para torná-los produtivos: biotecnologia e nanotecnologia. (HALL, 1962; TATON, 1966) ${ }^{1,2}$

\section{O NASCIMENTO DA ENGENHARIA QUÍMICA}

Os historiadores geralmente concordam que a engenharia química foi desenvolvida pelos americanos no início do século XX. Àquela época, a química orgânica já tinha quase um século e a química inorgânica era ainda mais antiga, pois se desenvolveu a partir do trabalho pioneiro, na década de 1780, de Antoine Lavoisier. Pequenas fábricas de produtos químicos inorgânicos eram muito comuns e, apesar de os produtos químicos orgânicos serem mais difíceis de se manipular e conservar, as indústrias que os utilizavam para fazer corantes e produtos farmacêuticos, encontravam-se relativamente avançadas.

A lucrativa indústria de produtos químicos orgânicos era dominada pela Alemanha. Suas empresas de corantes, as primeiras a perceber a importância de manter uma vantagem tecnológica, estabeleceram os primeiros laboratórios de pesquisa industrial do mundo, cooperando estreitamente com equipes de escolas de pós-graduação, outra instituição pioneira dos alemães. Juntos, eles fizeram da Alemanha a líder mundial em pesquisa de química, atraindo estudantes e profissionais de muitos outros países. (FURTER, 1980) ${ }^{3}$

Os três americanos que são considerados fundadores da engenharia química, William Hultz Walker, Warren Kendall Lewis e Arthur Dehon Little, estudaram na Alemanha. Assim que chegaram aos EUA, os americanos souberam que os alemães desenvolveram e industrializaram um processo para sintetizar amônia e produzir fertilizantes sintéticos comercialmente. Tal processo, denominado Haber-Bosch, foi vencedor de dois prêmios Nobel e é, até hoje, reconhecido como uma das maiores conquistas da engenharia química, apesar de não ter sido desenvolvido por engenheiros químicos: Fritz Haber era químico e Carl Bosch era engenheiro mecânico.

Há de se perguntar os motivos pelos quais os alemães não desenvolveram engenharia química já que, claramente, eles tinham cientistas competentes para isso. Os americanos certamente distinguiram as limitações alemãs e criaram as condições necessárias para a implantação da Engenharia Química nos EUA. Para entender estas questões, fazse necessário examinar as estruturas industriais nos dois países, bem como os conteúdos técnicos da própria engenharia química. (WEBER, 1980) ${ }^{4}$ 


\section{PRODUTOS E PROCESSOS DE PRODUÇÃO}

A fim de compreender os propósitos da engenharia química, deve-se distinguir o produto do processo de sua produção. Então, fica claro que um automóvel é um produto e sua produção em massa é um processo. Os consumidores que entram em contato apenas com produtos, raramente pensam em processos de produção. Porém, se os processos não forem eficientes, não é possível oferecer variedades do mesmo produto a preços acessíveis.

Produto e processo requerem engenharia, mas tipos diferentes de engenharia. Alunos em aulas de química agitam um tubo de ensaio ou agitam um béquer sobre uma chama para acelerar uma reação química. Plantas industriais simplesmente não podem agitar ou mexer um tanque de reagentes químicos de mil litros em um forno, não porque seja muito pesado, mas porque pode vir a ser letal. Assim, ampliar uma reação química do tubo de ensaio ao nível industrial requer muito conhecimento e esforço. Isso foi evidente no processo Haber-Bosch. $\mathrm{O}$ método de Haber para sintetizar amônia exigiu temperaturas de até $500{ }^{\circ} \mathrm{C}$ e pressões de até $1.000 \mathrm{~atm}$. Como essa alta pressão e temperatura eram enormemente difíceis de alcançar em escala industrial, sua invenção poderia ter permanecido como uma curiosidade de laboratório. Felizmente, a BASF, armada com a primeira instalação industrial de P\&D do mundo, investiu pesadamente no desenvolvimento de processos de grande escala. Foi nos processos de produção que a engenharia química encontrou seu nicho. (DUVALL \& JOHNSTON, 2000) ${ }^{5}$

Cabe entender o motivo pelo qual os alemães deixaram para os americanos a criação da engenharia química.

\section{PRODUTOS SOFISTICADOS E PESQUISA CIENTIFICA}

Os produtos químicos se apresentam em grande variedade, sendo usados em processos de fabricação como, por exemplo, agentes branqueadores nas indústrias têxtil e de papel. Em geral são divididos em duas classes: produtos químicos finos, como corantes e drogas, que são consumidos em quantidades menores e substâncias químicas pesadas, como ácido ou refrigerante, que são consumidas pela indústria em larga escala. (ASHTON, 1948) ${ }^{6}$
A indústria alemã era especializada principalmente em química fina. Esses produtos de alta tecnologia e alto valor exigiam uma química sofisticada para projetar e pessoal técnico para o mercado. A sintetização de novos corantes exigia química avançada e ampla pesquisa científica. As empresas de corantes estavam interessadas em fazer corantes para todas as cores do arco-íris visando desenvolver novas técnicas de marketing que ajudassem seus clientes a usar esses corantes sofisticados em tecidos da moda. Entretanto, como eles não tinham interesse em melhorar a eficiência dos processos de produção, milhares de corantes diferentes eram produzidos em pequena escala, tipicamente cem toneladas ou mais. Para essas quantidades, a produção era manejada por equipes de químicos e engenheiros mecânicos e o pequeno desperdício era facilmente absorvido na margem de lucro dos produtos de alto valor.

Quando viram oportunidades para novos produtos com demandas de larga escala, os alemães puderam mobilizar sua capacidade técnica em projetos especiais para desenvolver processos de produção, os quais eram mantidos fechados (proprietários) como o processo Haber-Bosch de amônia sintética e fertilizantes. Porém, casos como este, eram bastante singulares. Para o seu negócio principal de produtos químicos finos, os alemães não viram a necessidade de desenvolver um estudo dedicado a processos eficientes de produção em larga escala. (VALENTIN, 1940) 7

\section{PRODUÇÕES DE LARGA ESCALA E A CIÊNCIA DA ENGENHARIA}

A indústria americana produzia, principalmente, produtos químicos pesados. Essas commodities de baixa tecnologia e baixo valor exigiam pouca ou nenhuma ciência para projetar e eram produzidos em grandes quantidades. Para se ter uma ideia, os Estados Unidos produziram mais de dois milhões de toneladas de ácido sulfúrico em 1913 e suas margens de lucro eram tão pequenas que qualquer desperdício se tornava crítico. Esse volume de produção demandou características industriais que exigiam a criação de processos de produção eficientes, não apenas para esta ou aquela planta ou produto, mas para toda a indústria. Essa 
tarefa foi atendida pelos acadêmicos Walker, Lewis e Little que elaboraram uma engenharia baseada em abordagens científicas. (American Chemical Society) ${ }^{8}$

A indústria química pesada já existia há mais de um século, durante o qual os processos industriais foram desenvolvidos principalmente por experimentação, ou seja, tentativa e erro. A química industrial constituía um ramo distinto da química. Seus livros didáticos eram como livros de receitas que ofereciam roteiros nos quais as técnicas eram descritas, e os equipamentos eram listados para cada processo separadamente. Os procedimentos de um processo eram tidos como únicos e não aplicável a outros processos. Tedioso e repetitivo, a falta de princípios gerais dificultou a adaptação dos procedimentos. $\mathrm{O}$ conhecimento adquirido nas práticas industriais foi trancado em processos específicos e novos processos eram desenvolvidos empiricamente. Como a roda precisava ser inventada a cada processo, a tecnologia progrediu lentamente. (ASHTON, 1948) ${ }^{6}$

Descontentes com um roteiro extenso de processos industriais individualizados, Walker, Lewis e Little, do MIT, examinaram muitos processos químicos existentes e obtiveram leis gerais. Eles entenderam que no cerne do processamento químico industrial estavam as reações químicas que eram acompanhadas por mecanismos físicos, regidos pela termodinâmica e dinâmica dos fluidos. Ao serem implementados corretamente, estes princípios garantiriam os resultados desejados. Apesar dos mecanismos químicos e físicos interagirem de maneira complexa, eles exibiam certos padrões que os engenheiros químicos pioneiros se propuseram a analisar e obter uma expressão geral. Um processo genérico engloba a preparação de matérias-primas, reação química sob condições controladas, separação de produtos, subprodutos de reciclagem e descarte de resíduos. Cada estágio envolve certos "conjuntos básicos" de operação chamados de "operações unitárias" como, por exemplo, emulsificação, filtração e destilação. Como estas mesmas operações unitárias ocorriam em muitos processos, Walker, Lewis e Little foram pioneiros em introduzir uma estrutura conceitual geral para pensar sobre os processos químicos, delineando suas operações gerais. (DUVALL and JOHNSTON, 2000) $)^{5}$
O resultado da metodologia científica empregada pelos engenheiros do MIT foi a criação de um novo ramo da engenharia, a engenharia química. À medida que a ciência se desenvolveu ao longo das décadas, os engenheiros químicos buscaram entender os mecanismos subjacentes por meio de teorias matemáticas que tornassem possível calcular e prever o desempenho de plantas de processamento, sem a necessidade de uma experimentação dispendiosa. Essa ciência da engenharia química conferiu grandes vantagens econômicas. Plantas e matérias-primas eram responsáveis por um percentual maior de custos nas indústrias químicas do que em outras manufaturas, em que os custos de mão-deobra eram mais altos. Os custos de capital, em grande parte no financiamento, são especialmente altos para produções de larga escala, podendo consumir até metade da receita do produto. Os altos custos de capital valorizaram a capacidade de entender os princípios operacionais no estágio de planejamento e projeto. Assim, ajustar e modificar plantas caras, que atrasavam a operação e aumentavam os custos financeiros, eram e são fundamentais. (BOWDEN, 1997) ${ }^{3}$

Comparamos as indústrias americanas e alemãs, mas a indústria britânica era semelhante à americana. Então, quais os motivos que levaram a Engenharia Química a ser desenvolvida na América? Provavelmente, as atitudes acadêmicas e governamentais da Grã-Bretanha desempenharam um papel relevante nessa questão. As grandes universidades britânicas do eixo Oxbridge não valorizavam nem demonstravam entusiasmo em fornecer educação técnica, em função do forte preconceito da aristocracia inglesa em relação à entrada de discentes provenientes da burguesia inglesa. Tal postura é frequentemente citada como uma razão para o relativo declínio tecnológico e econômico da Grã-Bretanha em final do século XIX. Em comparação, a atmosfera na América era mais pragmática. Apesar de algumas universidades compartilharem do "esnobismo britânico", estas foram submetidas à uma forte pressão competitiva em 1862 pelo ato educacional denominado Morrill Land Grant College Act que forneceu terras do governo às faculdades que oferecessem cursos de "artes agrícolas e mecânicas". Entre as várias universidades que atenderam ao Ato, encontra- 
se a instituição Massachusetts Institute of Technology, que recebeu um grande incentivo financeiro, tornando-se extremamente competitiva. (WEBER, 1980) ${ }^{4}$

\section{Considerações Finais}

O conhecimento a ser desenvolvido nos conteúdos de um curso de engenharia química envolve a estrutura dos fenômenos naturais que a engenharia química utiliza e a estrutura das necessidades industriais e sociais as quais ela serve. A engenharia alemã sempre foi de excelência, porém seus engenheiros mecânicos eram treinados mantendo sua expertise restrita a si próprios. Suas competências e habilidades não foram sistematicamente desenvolvidas e a tecnologia por eles desenvolvida era de propriedade da corporação. Era um conhecimento "localizado" e não adequado para globalização.

Nos Estados Unidos, a engenharia química foi desenvolvida por professores universitários voltados para a educação. Seu conhecimento foi sistematicamente apresentado para estudantes que poderiam sair para trabalhar em qualquer lugar. Era uma ciência aberta à generalização e adaptação. (SPITZ, 1980) ${ }^{9}$

Armados com conhecimento científico, os engenheiros químicos americanos foram capazes de desenvolver, rapidamente, processos para novas reações químicas. Um triunfo foi a produção da penicilina durante a Primeira Guerra Mundial, na qual os processos foram estendidos da química para a bioquímica. Outro foi o desenvolvimento para a refinaria de petróleo de craqueamento catalítico em leito fluidizado a partir do processo Houndry. O MIT colaborou de perto com a Standard Oil de Nova Jersey para desenvolver o processo, instruiu estudantes em locais industriais e avançou princípios de engenharia química simultaneamente enquanto construíam a planta piloto. $(\text { MOSELEY, 1984) })^{10}$

Processos químicos específicos podem ser mantidos proprietários pelas empresas, mas princípios gerais não podem. Os engenheiros formaram firmas de consultoria, muitas das quais possuíam seu próprio departamento de
P\&D. Essas empresas assumiram o desenvolvimento, construção e até mesmo treinamento de pessoal referente ao projeto. Essa era uma estrutura industrial nova, resultando em uma indústria petroquímica altamente aberta e competitiva. Os hidrocarbonetos contidos no petróleo bruto são matéria-prima para muitos produtos químicos orgânicos. Hoje, a maioria dos plásticos, resinas, fibras sintéticas, amônia, metanol e produtos químicos orgânicos são fabricados com petróleo ou gás natural como matériaprima. Eles são chamados petroquímicos e existem milhares deles. A fabricação de cada um deles requer um processo diferente, e a disponibilidade da ciência da engenharia química desempenhou um papel crucial na proliferação quase instantânea da indústria petroquímica após a Segunda Guerra Mundial ${ }^{10-12}$.

\section{Referências}

1. American Chemical Society National Historic Chemical Landmarks. The Houdry Process for Catalytic Cracking. Acesso em 27 de julho de 2018: http://www.acs.org/content/acs/en/education/ whatischemistry/landmarks/houdry.html

2. Ashton, T. S. The Industrial Revolution, 1760-1880, London, 1948.

3. Bowden, M. E. Chemical achievers: the human face of the chemical sciences. Philadelphia, PA: Chemical Heritage Foundation, 1997.

4. Duvall, C. and JOHNSTON, S. F. Scaling Up: The Institution of Chemical Engineers and the Rise of a New Profession, Kluwer Academic. Dordrecht, Netherlands, 2000.

5. Furter W. F. A Century of Chemical Engineering, Plenum Press. NY \& London, 1980.

6. Hall, A.R. The Scientific Revolution, 1500-1800, Boston, 1962.

7. Moseley, Charles G. Eugene Houdry, Catalytic Cracking, and World War II Aviation Gasoline. Journal of Chemical Education, 61, 1984.

8. Servos, John W. Physical chemistry from Ostwald to Pauling: the making of a science in America. Princeton, N.J.: Princeton University Press, 1990.

9. Spitz, Peter H. Petrochemicals: The Rise of an Industry. New York: John Wiley \& Sons, 1988.

10. Taton, R. A General History of the Sciences, New York, 1966.

11. Valentin, V. 1848: Chapters of German History, New York, 1940.

12. Weber H.C. The Improbable Achievement: Chemical Engineering at MIT, MIT, Cambridge, MA, 1980. 
Alberto V. da Silva, Claudia G. D. de Abreu, Josie C. Barbosa, Marta C. Picardo* \& Ronaldo L. Souza

SENAI CETIQT. Centro de Tecnologia Rua Magalhães Castro 174 - Riachuelo. CEP: 20961-020 - Rio de Janeiro - RJ

*E-mail: mcpicardo@cetiqt.senai.br 